\title{
The Pandemic, Lockdown and Employment
}

\author{
Ajit K. Ghose ${ }^{1}$
}

Published online: 19 September 2020

(c) Indian Society of Labour Economics 2020

The COVID-19 generated a public health crisis in India, and the government's response to it generated an employment crisis. The nationwide lockdown that was imposed to contain the spread of the virus also meant an effective shutdown of a large part of the economy for a period of two months. In an economy such as India's, where employment conditions remained poor even after years of rapid economic growth, the adverse effects of the economic shutdown on employment and livelihoods have been huge and immediate. How, when and to what extent these will be reversed are not easy to predict.

In this note, I attempt to develop a concrete view of the nature and magnitude of the immediate effects of the economic shutdown on employment in the economy. I do this in two steps. In the first step, I consider the structure of employment in 2018, which can be taken to be the structure of employment that existed before the shutdown shock hit the economy. This provides a basis for assessing the type and quantity of employment that could be regarded as potentially most vulnerable to the shock. Based on this assessment, at the second step, I develop estimates of the magnitude of loss of employment of different types that the economic shutdown is most likely to have caused. I conclude with a few observations on post-lockdown prospects of reversal of trends, that is, of rehabilitation of lost employment and livelihoods.

\section{Economic Shutdown and Employment}

Judgement about vulnerability of employment to the shock of an economic shutdown has to be based on two basic considerations. The first relates to types of employment: certain types of employment can speedily disappear in times of economic crisis, while other types suffer partial or even no loss. In India, there are four basic types of employment: regular-formal wage employment, regular-informal wage employment, casual wage employment and self-employment (Ghose 2016). The type of wage employment that is most vulnerable is casual wage employment-daily

Ajit K. Ghose

ghose.ajit@gmail.com

1 Institute for Human Development, New Delhi, India 
employment on a daily wage; persons in employment of this type face immediate loss of job and livelihood in the case of cessation of the economic activities they are engaged in. Regular-informal wage employment-salaried jobs that offer no security of tenure or social protection-is also vulnerable though less so than casual wage employment. A large section of the self-employed operates with poor asset base and hence is vulnerable to shocks. Only $4 \%$ of the self-employed are employers (who use mainly hired labour) who can be regarded as having a reasonably secure base. Many of the rest - the own account workers and the unpaid family workersare vulnerable to economic shocks. The only kind of employment that can be considered secure is regular-formal wage employment-salaried jobs that offer some degree of security of tenure and some form of social protection; shutdown of activities does not automatically mean termination of these jobs.

The second consideration relates to sectors of economic activity; these have been unevenly affected by the lockdown. And we know in broad terms the extent of shutdown in particular sectors.

We know that agricultural activities were not directly affected by the lockdown. They were nevertheless not entirely unaffected; the mobility restrictions created labour shortages in peak season operations such as harvesting, and the disruptions in transport and marketing systems caused wastage, particularly in the case of perishables. The non-agricultural sectors can be divided into two groups: non-agriculture 1, which includes manufacturing; construction; mining; trade, hotels and restaurants; transport; and other services, and non-agriculture 2, which includes utilities; communication; financial and business services; education and health services; and public administration and defence. The lockdown meant near-complete shutdown of activities in non-agriculture 1 but only partial or no shutdown of activities in nonagriculture 2. Overall, the extent of the shutdown was large in the case of non-agriculture 1, significant in the case of agriculture and small in the case of non-agriculture 2 .

The data in Table 1 show the structure of employment in 2018, which we assume to be the structure of employment that existed on the eve of the lockdown. The noteworthy features for our purpose are as follows. First, in agriculture, which employed $41 \%$ of all workers in the economy, $95 \%$ of the employment can be regarded as

Table 1 Employment situation, 2018

\begin{tabular}{|c|c|c|c|c|c|}
\hline & \multicolumn{5}{|c|}{ Number in employment in millions } \\
\hline & Regular-formal & Regular-informal & Casual & Self- & Total \\
\hline Agriculture & $1(2)$ & $2(3)$ & $49(43)$ & $139(59)$ & $191(41)$ \\
\hline Non-agriculture 1 & $16(35)$ & $49(72)$ & $63(56)$ & $91(38)$ & $219(47)$ \\
\hline Non-agriculture 2 & $29(63)$ & $17(25)$ & $1(1)$ & $7(3)$ & $54(12)$ \\
\hline Economy & $46(100)$ & $68(100)$ & $113(100)$ & $237(100)$ & $464(100)$ \\
\hline Percentage distribution & 10 & 15 & 24 & 51 & 100 \\
\hline
\end{tabular}

Figures in parentheses show percentages

Source: Author's estimates based on data from the Periodic Labour Force Survey (2017-2018) 
Table 2 Distribution of persons in different types of employment by level of education, 2018

\begin{tabular}{lclcc}
\hline & Regular-formal & $\begin{array}{l}\text { Regular- } \\
\text { informal }\end{array}$ & Casual & Self- \\
\hline Not literate & 2.2 & 12.2 & 38.2 & 26.1 \\
Up to primary & 3.8 & 16.5 & 25.7 & 20.3 \\
Up to secondary & 21.4 & 39.8 & 31.0 & 35.9 \\
Above secondary & 72.6 & 31.5 & 5.1 & 17.7 \\
\hline
\end{tabular}

Source: Same as in Table 1

\begin{tabular}{lllrrr}
\hline & $\begin{array}{l}\text { Regu- } \\
\text { lar-for- } \\
\text { mal }\end{array}$ & $\begin{array}{l}\text { Regular- } \\
\text { informal }\end{array}$ & Casual & Self- & Total \\
\hline Number of jobs lost (in millions) & & & & \\
Agriculture & 0 & 1 & 20 & 35 & 56 \\
Non-agriculture 1 & 0 & 25 & 63 & 60 & 148 \\
Non-agriculture 2 & 0 & 4 & 1 & 7 & 12 \\
Economy & 0 & 30 & 84 & 102 & 216 \\
Percent of jobs lost & & & & & \\
Agriculture & 0 & 50 & 41 & 25 & 29 \\
Non-agriculture 1 & 0 & 50 & 100 & 66 & 67 \\
Non-agriculture 2 & 0 & 25 & 100 & 100 & 22 \\
Economy & 0 & 44 & 78 & 43 & 47 \\
\hline
\end{tabular}

Table 3 Estimates of job losses caused by the lockdown vulnerable (regular-formal employment and self-employment as employers having been considered non-vulnerable). Second, non-agriculture accounted for $59 \%$ of total employment in the economy, but a very large part (81\%) of the non-agricultural employment was in non-agriculture 1 , which was the sector most severely affected by the lockdown. Moreover, bulk (92\%) of the employment in non-agriculture 1 was of the vulnerable kind (regular-informal wage employment, casual wage employment and self-employment). Third, much (63\%) of the secure employment (i.e., regular-formal employment) in the economy was in non-agriculture 2, where employment of this kind also accounted for a large part (53\%) of total employment.

We know that the different types of employment fall into a neat hierarchical order with respect to levels of education and income status of the employed. As the data in Table 2 show, the regular-formal employees are the most educated and the casual employees are the least educated; regular-informal employees are more educated than the self-employed. The hierarchical order with respect to income status, perhaps not surprisingly, is exactly the same: the income level is highest for the regular-formal employees, the second-highest for the regular-informal employees, the thirdhighest for the self-employed and the lowest for the casual employees (Ghose 2016). It is clear that the "poor and less educated" were mostly in vulnerable employment, while the "well-off and educated" were mostly in secure employment.

Our estimates of employment loss caused by the lockdown are set out in Table 2. The bottom part of Table 3 shows the assumptions about the extent of the loss of 
Table 4 Employment losers as percent of the employed

\begin{tabular}{llll}
\hline & $\begin{array}{l}\text { Regular } \\
\text { employees }\end{array}$ & $\begin{array}{l}\text { Casual } \\
\text { employees }\end{array}$ & Self-employed \\
\hline Rural economy & 59 & 66 & 62 \\
Urban economy & 67 & 82 & 79 \\
\hline
\end{tabular}

\begin{tabular}{lccrc}
\hline & Regular & Casual & Self- & Total \\
\hline Number of employed (in millions), & 2018 & & \\
Rural economy & 40 & 90 & 177 & 307 \\
Urban economy & 74 & 23 & 60 & 157 \\
Economy & 114 & 113 & 237 & 464 \\
Employment lost (in millions) & & & \\
Rural economy & 24 & 59 & 110 & 193 \\
Urban economy & 50 & 19 & 47 & 116 \\
Economy & 74 & 78 & 157 & 309 \\
\hline
\end{tabular}

Table 5 Alternative estimates of job losses caused by the lockdown different types of employment in each of the three component parts of the economy. These assumptions reflect our judgements based on the considerations discussed above. The main assumptions are stated explicitly as follows: no regular-formal employee lost a job; all casual employees in non-agriculture lost jobs; most of the self-employed in non-agriculture had to stop working; among the self-employed in agriculture only the unpaid family workers lost employment; and for the regular-informal employees, job loss was less serious in non-agriculture 2 than in agriculture and non-agriculture 1.

Overall, $47 \%$ of the employed suffered loss of employment. On a simple projection, the total number of employed in the economy on 1 March 2020 would have been 482 million. Thus, 227 million persons may have lost employment because of the economic shutdown. Of the employment losers, 32 million (14\%) had been regular-informal employees, 89 million (39\%) had been casual employees and 107 million (47\%) had been self-employed. Clearly, a large majority of the employment losers were "poor and less educated". Thus, the employment decline had the effect of increasing both poverty and inequality.

It is of some interest to compare our estimates above with the alternative estimates that can be derived by using the results of COVID-19 Livelihoods Survey (see Lahoti et al. 2020 for discussions of the survey and the data) conducted by the Centre for Sustainable Employment, Azim Premji University, which are presented in Table 4.

By using these proportions together with our estimates of employment in 2018, we can derive alternative estimates of employment loss, which are presented in Table 5. According to these estimates, $67 \%$ of the employed suffered loss of employment in consequence of the economic shutdown (compared to $47 \%$ according to our earlier estimates). Assuming the number in employment on 1 March 2020 to be 482 million, the number of employment losers works out to 323 million, which is much higher than our Springer ISLE 
estimate of 227 million. Of the 323 million employment losers, 77 million (24\%) had been regular employees, 82 million (25\%) had been casual employees and 164 million $(51 \%)$ had been self-employed. Once again, a large majority of the employment losers were "poor and less educated".

One could quibble with the precise numbers whose derivation is not completely devoid of arbitrariness. But beyond quibble are the conclusions that the lockdown has caused employment loss on a massive scale and that a very large majority of the employment losers have been the "poor and less educated" workers.

\section{Reviving Employment: A Formidable Challenge}

What would it take to revive employment in India of tomorrow? The economic shutdown was a large supply-side shock, which then led to a collapse of demand. Given the nature and magnitude of employment loss caused by the shutdown, there have been large income loss and significant increase in income inequality; both developments contributed to demand collapse. In this setting, economic revival requires "big push", i.e., simultaneous revival of all economic activities that suffered shutdown. This is what can restore demand (through employment revival) together with supply.

Achieving such a "big push" obviously presents a huge challenge, and it is difficult to see how it can be done. Even if the shutdown had ended, reactivation of factories and workspaces, restoration of transport and logistics and undoing of the disruptions in global and national supply chains would have been immensely difficult tasks. But the shutdown has not really ended. While the national lockdown has ended, localised lockdowns continue and when these might end is hard to predict. In such a context, "big push" is pipe dream.

If we consider the medium term, when (we can suppose) the pandemic and shutdown are truly over, the challenge of employment revival appears no less formidable. The economy will not just be smaller but also structurally changed. The importance of the sectors that have not suffered shutdown will have increased; growth of these sectors is unlikely to generate employment at a rapid rate and certainly will not generate employment for "poor and less educated" workers. The shutdown, moreover, has had the effect of boosting digitisation, e-commerce and platform economy. It has also generated strong incentives for entrepreneurs to pursue automation irrespective of its profitability. All of these developments will make employment revival extremely difficult.

\section{References}

Ghose, A.K. 2016. India Employment Report 2016. New Delhi: Oxford University Press and The Institute for Human Development.

Lahoti, R., A. Basole, R. Abraham, S. Kesar, and P. Nath. 2020. Hunger grows as India's lockdown kills jobs. The India Forum 5 June 2020.

Publisher's Note Springer Nature remains neutral with regard to jurisdictional claims in published maps and institutional affiliations. 